\title{
Volume-dependent hemodynamic effects of blood collection in canine donors - evaluation of $13 \%$ and $15 \%$ of total blood volume depletion
}

\author{
RUI R.F. FERREIRA ${ }^{1}$, RAFAEL R. GOPEGUI ${ }^{2}$ and AUGUSTO J.F. DE MATOS ${ }^{3}$ \\ ${ }^{1}$ ICBAS-UP, Departamento de Clínicas Veterinárias, Instituto de Ciências Biomédicas de Abel Salazar, \\ Universidade do Porto, Rua de Jorge Viterbo Ferreira, 228, 4050-313 Porto, Portugal \\ ${ }^{2}$ Departamento de Medicina e Cirurgia da Faculdade de Veterinária, \\ Universidade Autónoma de Barcelona, Bellaterra, 08193, Barcelona, Spain \\ ${ }^{3}$ Unidade Multidisciplinar de Investigação em Biomedicina/UMIB, \\ Rua de Jorge Viterbo Ferreira, 228, 4050-313 Porto, Portugal \\ Manuscript received on April 30, 2014; accepted for publication on September 9, 2014
}

\begin{abstract}
Background: There is no consensus regarding the blood volume that could be safely donated by dogs, ranging from 11 to $25 \%$ of its total blood volume (TBV). No previous studies evaluated sedated donors. Aim: To evaluate the hemodynamic effects of blood collection from sedated and non-sedated dogs and to understand if such effects were volume-dependent. Materials and Methods: Fifty three donations of 13\% of TBV and 20 donations of $15 \%$ TBV were performed in dogs sedated with diazepam and ketamine. Additionally, a total of 30 collections of $13 \%$ TBV and 20 collections of $15 \%$ TBV were performed in nonsedated dogs. Non-invasive arterial blood pressures and pulse rates were registered before and 15 min after donation. Results: Post-donation pulse rates increased significantly in both sedated groups, with higher differences in the $15 \%$ TBV collections. Systolic arterial pressures decreased significantly in these groups, while diastolic pressures increased significantly in 13\% TBV donations. Non-sedated groups revealed a slight, but significant, SBP decrease. No clinical signs related to donations were registered. Conclusion: These results suggest that the collection of $15 \% \mathrm{TBV}$ in sedated donors induces hemodynamic variations that may compromise the harmlessness of the procedure, while it seems to be a safe procedure in non-sedated dogs.
\end{abstract}

Key words: blood donation, dog, sedation, volume.

\section{INTRODUCTION}

In the latest decades, canine transfusion medicine has been receiving growing attention, with particular emphasis on blood components therapy, transfusion triggers, compatibility, and transfusion reactions (Gibson and Abrams-Ogg 2012, Mathews et al. 2006, Schneider 1995). However, health and welfare of blood donors is scarcely mentioned in

Correspondence to: Rui Manuel Roque Fundo Ferreira

E-mail: ruiferreira@bsanimal.com scientific studies. Consequently, there is currently no consensus on the ideal frequency of donations, the blood volumes that can safely be collected or the effects of sedation in such procedures. Previously published studies vary both in volume and frequency of donations. Proposed protocols include the collection of volumes ranging from 10 to $22 \mathrm{ml} / \mathrm{kg}$ every 21-28 days without any nutritional supplement (Ford and Mazzaferro 2006, Gibson and AbramsOgg 2012, Mathews et al. 2006, Schneider 1995) or 
every 10-21 days with iron supplement (Authement 1991). According to these data, and assuming a TBV of $85-90 \mathrm{ml} / \mathrm{kg}$ (Post 2000), 10 to $25 \%$ TBV can be collected in each procedure. The depletion effects were identified as an immediate postdonation decrease of the systolic blood pressures of non-sedated donors submitted to the collection of 17-22\% TBV (Couto and Iazbik 2005). To authors' knowledge, this was the only clinical study performed in canine blood donors addressing hemodynamic effects, however it only studied Greyhounds, which have a lot of specific physiologic peculiarities that hamper extrapolation of results to other breeds. In humans, the Council of Europe recommends up to four blood donations per year in men and up to three in women, with a maximum volume of $13 \% \mathrm{TBV}$ (Council 2011), while the United Kingdom Blood Transfusion Services recommend a maximum of three annual donations for both genders (UK 2005). Differences between both species could be related to a donation-related vasovagal reaction (VVR), a very important adverse effect in humans with reported prevalences ranging from 0.87 to $7 \%$ (Newman 2004, Newman et al. 2003, Zervou et al. 2005). The vasovagal reaction, a complex and still poorly understood mechanism, results in cardio inhibitory and vasodepressive effects (TrouernTrend et al. 1999) that can be associated with the hypovolemic state induced by volume depletion; the orthostatic hypotensive effect, as well as the associated psychological stress caused by fear of needles, pain and the sight of blood (Wieling et al. 2011). In dogs, only volume depletion can be related to VVR, because the quadruped position prevents the orthostatic effect, which could explain why dogs have lower incidences of VVR, hence tolerating the collection of higher blood volumes.

Due to the less than optimal behavior of some canine donors, blood banks face two options: either to eliminate such animals from the donation program or to sedate them in order to proceed according to the best and safest methods. The first option results in a significant loss of resources, while the second allows for a better planning of the program and for the use of the safest and more efficient methods, both in order to ensure the quality of the final product and also, and foremost, to ensure the comfort and safety of the donor.

It is known that sedation has hemodynamic effects, namely inotropic and chronotropic, that, when combined with the blood depletion inherent to the procedure, may induce risk to donor's welfare and health. However, to the authors' knowledge no studies were performed on sedated blood donors.

Our study aimed to evaluate the hemodynamic effects of blood collection from sedated dogs and to understand if such effects were volume-dependent. Since the combined effects of sedation and blood depletion had never been evaluated, the authors refrained from collecting large volumes of blood. Therefore, volumes were chosen on the basis of the maximum recommended for human blood banks $(13 \%)$ and the value more often described in the veterinary literature $(15 \%)$.

\section{MATERIALS AND METHODS}

The study protocol was approved by the ICBASUP Ethics Committee (Project number 008/2012) and an informed consent was obtained from each owner. All animals were mixed-breed healthy 1-7 years old dogs, weighing 21-45 kg, that had been vaccinated, dewormed and had normal complete blood count parameters and serum values of alkaline phosphatase, alanine aminotransferase, creatinine, total proteins and glucose. Furthermore, they all test negative in the Polymerase Chain Reaction analysis for Anaplasma spp., Ehrlichia spp., Babesia canis, Leishmania infantum, and Dirofilaria immitis. When required, canine donors unable to keep still, were sedated and randomly submitted to the collection of 13\% TBV (group 1 ) and $15 \%$ of TBV (group 2). Non-sedated dogs were also randomly selected to donate $13 \%$ (group 3 ) and 15\% TBV (group 4). 
Physical exam and measurement of arterial blood pressures were performed before each procedure, after placing the donors in lateral recumbency over the donation table. Donors from groups 1 and 2 were sedated with diazepam $0.5 \mathrm{mg} /$ $\mathrm{kg}$, IV (Valium, Roche ${ }^{\circledR}$ ) and ketamine $5 \mathrm{mg} / \mathrm{kg}$, IV (Clorketam, Vetoquinol ${ }^{\circledR}$ ), administered over one minute using a catheter placed in the cephalic vein. In both sedated and non-sedated dogs the puncture site over a jugular vein was clipped of hair and aseptically prepared (chlorhexidine and alcohol). These procedures lasted less than 5 minutes and were followed by jugular venepuncture allowing the blood to flow by gravity into the collection bag. The total collected volumes were calculated on the basis of the dogs weight, assuming that canine TBV is $85 \mathrm{ml} / \mathrm{kg}$ (Jahr et al. 2008) and that $1 \mathrm{ml}$ of whole blood weights $1.053 \mathrm{~g}$ (Kakaiya et al. 2011). Once the total volume was obtained, the collection tube was sealed. Within 15 min after blood collection, capillary refill times (CRT), pulse rates and arterial blood pressures were re-evaluated. From collection to discharge, all dogs were qualitatively monitored for changes in mental status and activity levels, and after discharge owners were requested to report any abnormalities within the next $48 \mathrm{hr}$.

Non-invasive systolic arterial pressure (SAP), mean arterial pressures (MAP) and diastolic arterial pressure (DAP), were evaluated by the oscilometric method (Dinamap Carescape V100, General Electrics ${ }^{\circledR}$ ) in the metatarsal artery, with dogs in lateral recumbence on the donation table in a quiet non-stressful environment, using cuff widths that were equivalent to $40 \%$ of the leg diameter where the measurements were made. The first value was discarded and the seven subsequent measurements were registered, if deemed consistent (less than 20\% variation). Abnormal readings caused by unexpected movements were also discarded. The mean of each pressure was calculated from five registered measurements, after rejection of the lowest and highest values. Pulse rates were measured by digital palpation of the femoral arteries during $60 \mathrm{sec}$. CRT was measured on the labial mucosa.

Results were analyzed using SPSS statistical software. Normal distribution of data was assessed with the Kolmogorov-Smirnov test. Paired sample Student's t-test was used to compare differences between measurements of pulse rate, SAP, MAP and DAP registered before and after each blood collection. One-way ANOVA was used to compare the group differences of the post-donation values. Specific significant differences between each group were identified by a post hoc Bonferroni test. The critical probability for statistical significance was taken to be $\mathrm{P} \leq 0.05$.

\section{RESULTS}

Complete data from 123 blood collections were registered, including 83 dogs donating 13\% TBV (53 sedated and 30 non-sedated) and $40 \mathrm{dogs}$ donating 15\% TBV (20 sedated and 20 nonsedated). The collection procedures lasted less than $15 \mathrm{~min}$, sedation recovery times ranged between 40 and $70 \mathrm{~min}$ and all dogs went home within $3 \mathrm{hr}$ after collection. No donation-related clinical signs were evident in the hospital nor reported by the owners. CRT was $\leq 1$ second in all measurements.

Pre- and post-donation values for each variable were normally distributed and are presented in Table I and figures 1-3. In groups 1 and 2 there was a small, albeit significant, post-donation reduction of the mean systolic pressures (SAP), accompanied by a small increase of the mean diastolic pressures (DAP), that reached significance in group 1 . Significantly higher post-donation pulse rates were observed in both groups, with the mean of group 2 surpassing $180 \mathrm{ppm}$ and in $30 \%$ of the collections surpassing $210 \mathrm{ppm}$. In the non-sedated groups (groups 3 and 4), only SAP decreased significantly, with no significant variation of the pulse rates. When comparing the post-donation values of sedated dogs, group 2 presented significantly higher pulse rates than the remaining groups. 
TABLE I

Pre- and post-donation pulse rates, SAP, MAP and DAP. Paired sample Student's t-test and one-way ANOVA were used to compare differences between pulse rate, SAP, MAP and DAP before and after blood collections, and to compare the post-donation group differences.

\begin{tabular}{|c|c|c|c|c|c|c|}
\hline & \multicolumn{2}{|c|}{ Pre-donation } & \multicolumn{2}{|c|}{ Post-donation } & \multirow[t]{2}{*}{$\mathrm{t}$ value } & \multirow[t]{2}{*}{$\mathrm{p}$ value } \\
\hline & $\mathrm{M}$ & SD & $\mathrm{M}$ & SD & & \\
\hline \multicolumn{7}{|c|}{ Group $1(\mathrm{~N}=53)$} \\
\hline ppm & 116.09 & 18.70 & $154.62^{\mathrm{a}, \mathrm{b}}$ & 30.82 & -9.583 & .000 \\
\hline DAP & 86.43 & 16.65 & $93.28^{\mathrm{c}}$ & 17.55 & -3.099 & .003 \\
\hline MAP & 107.04 & 15.33 & $111.58^{d}$ & 19.22 & -2.009 & .050 \\
\hline SAP & 145.88 & 15.35 & 139.61 & 21.35 & 2.674 & .010 \\
\hline \multicolumn{7}{|c|}{ Group $2(\mathrm{~N}=20)$} \\
\hline ppm & 117.40 & 17.56 & $183.65^{\mathrm{a}, \mathrm{e}}$ & 32.61 & -8.469 & .000 \\
\hline DAP & 80.20 & 10.23 & 82.85 & 10.86 & -.762 & NS \\
\hline MAP & 103.80 & 8.45 & 101.05 & 12.39 & .813 & NS \\
\hline SAP & 141.10 & 9.84 & 131.85 & 16.69 & 3.902 & .001 \\
\hline \multicolumn{7}{|c|}{ Group $3(\mathrm{~N}=30)$} \\
\hline ppm & 117.53 & 21.39 & $120.33^{\mathrm{b}}$ & 25.24 & -.529 & NS \\
\hline DAP & 84.01 & 15.10 & $82.50^{c}$ & 16.36 & .592 & NS \\
\hline MAP & 105.75 & 15.90 & $99.33^{\mathrm{d}}$ & 16.18 & 3.165 & .004 \\
\hline SAP & 141.74 & 18.99 & 127.53 & 21.57 & 7.073 & .000 \\
\hline \multicolumn{7}{|c|}{ Group $4(\mathrm{~N}=20)$} \\
\hline ppm & 119.85 & 15.38 & $111.60^{\mathrm{e}}$ & 24.28 & 1.476 & NS \\
\hline DAP & 77.75 & 10.97 & 73.05 & 11.43 & 1,248 & NS \\
\hline MAP & 99.30 & 11.29 & 91.55 & 13.66 & 3.661 & .003 \\
\hline SAP & 142.65 & 11.78 & 123.15 & 17.02 & 8.611 & .000 \\
\hline
\end{tabular}

$\mathrm{M}$ - mean; NS- non-significant.

${ }^{\mathrm{a}} \mathrm{p}=.001 ;{ }^{\mathrm{b}} \mathrm{p}<.001 ;{ }^{\mathrm{c}} \mathrm{p}=.017 ;{ }^{\mathrm{d}} \mathrm{p}=.010 ;{ }^{\mathrm{e}} \mathrm{p}<.001$.

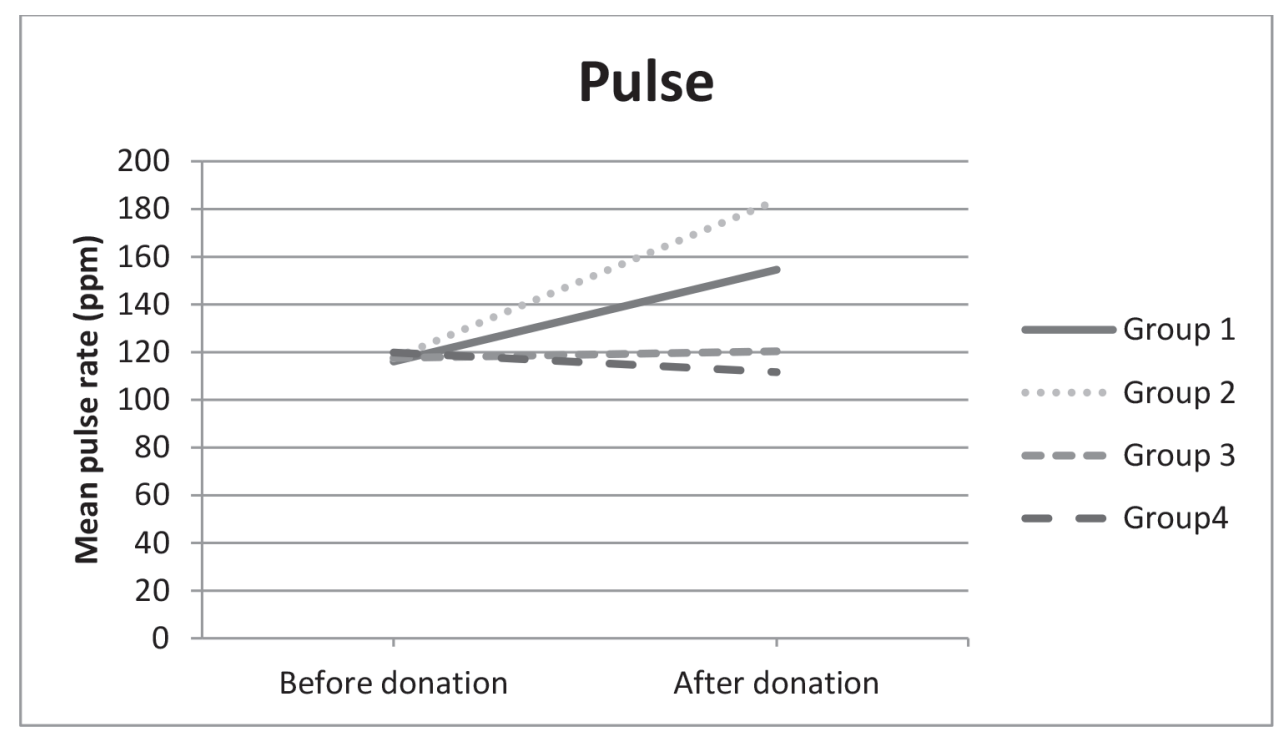

Figure 1 - Mean pulse rates evidenced before and after the blood collection in each group. 


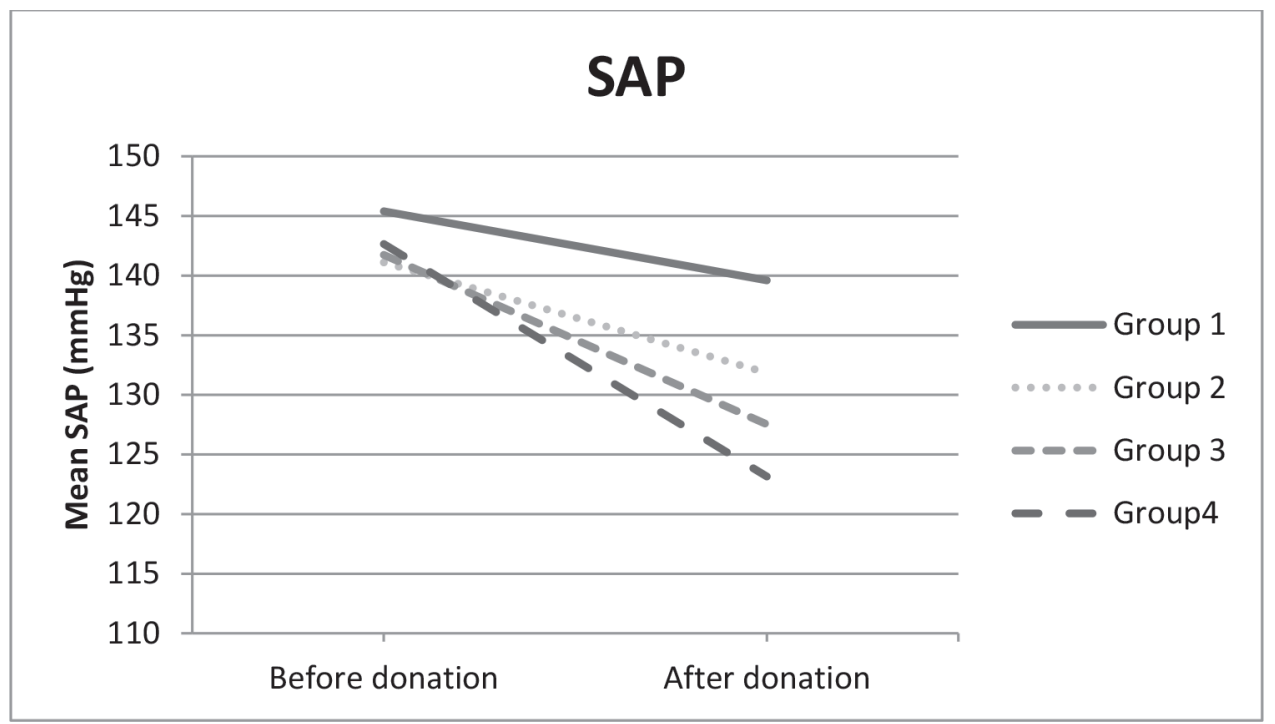

Figure 2 - Mean SAP values evidenced before and after the blood collection in each group.

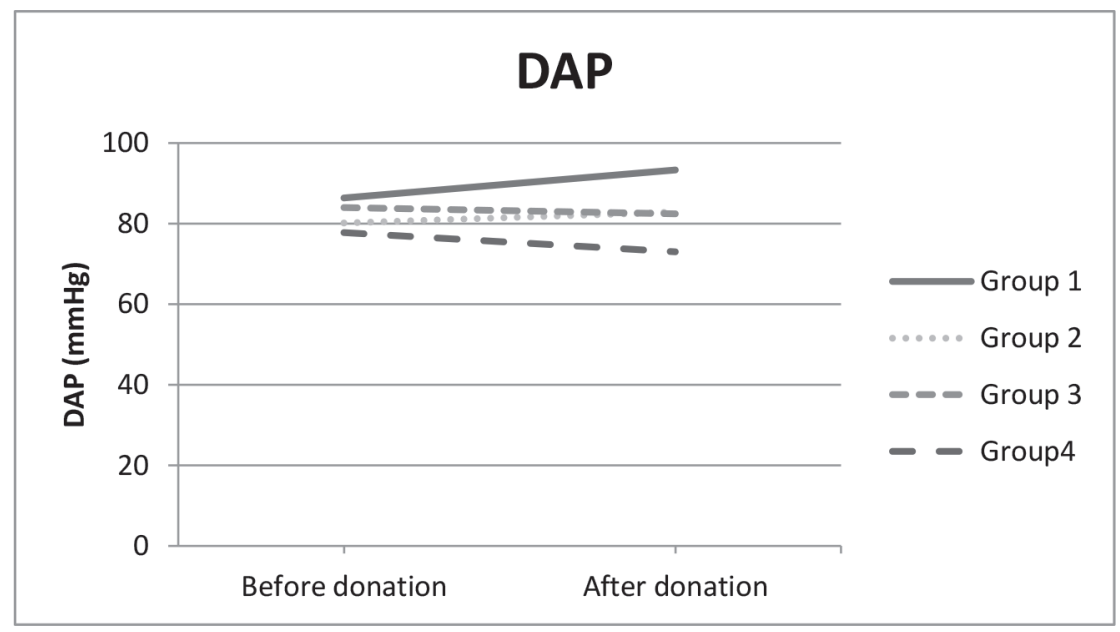

Figure 3 - Mean DAP values evidenced before and after the blood collection in each group.

\section{DISCUSSION}

This study aimed to evaluate the hemodynamic effects of blood depletion in sedated and nonseated canine blood donors, and to understand if its amplitude was volume-dependent.

Ketamine is a fast acting general anesthetic and analgesic that induces anesthetic stages I and II (Plumb 2005). Its cardiovascular effects are due to an increased sympathetic tone and include higher cardiac output, heart rate, aortic, pulmonary artery, and central venous pressures, while its effects on total peripheral resistance have been described as variable (Lysa and Posner 2009a, Plumb 2005). Diazepam is frequently added to ketamine, in order to provide good muscle relaxation and add sedative and anxiolytic effects (Lysa and Posner 2009a, Plumb 2005). This is a fast-acting, short duration combination, with no cardiopulmonary depressant effects, that produces adequate relaxation and immobility (Lysa and Posner 2009a, Plumb 2005). Furthermore, the absence of hypotension effects or peripheral vasoconstriction, frequently associated 
with other sedative agents, facilitates the blood collection process, ensuring very good venous access which enables a quick and easy procedure. Other sedative agents that had been described for use in blood collections include butorphanol (Mathews et al. 2006), hydromorphone (Lester 2012, Mathews et al. 2006), acepromazine (Mathews et al. 2006) and dexmedetomidine (Lester 2012). Even though butorphanol has analgesic properties and induces central nervous system depression in dogs, it may reduce heart rate and decrease arterial blood pressures, by increased parasympathetic tone (Plumb 2005). Hydromorphone has analgesic and sedative properties but may induce respiratory depression, bradycardia, vomiting and constipation (Plumb 2005). Acepromazine has important hypotensive effects and should be avoided to minimize postdonation hypotension (Mathew and Abramsogg 2006, Plumb 2005). Dexmedetomidine, an alpha-2-adrenergic agonist, causes a profound peripheral vasoconstriction that, when associated to its negative chronotropic and inotropic effects, hampers adequate blood collection by decreasing velocity of blood flow (Lysa and Posner 2009). One limitation of our study was the lack of a control group with animals subjected to a sedation protocol without blood collection. However, the inclusion of such group would have been ethically unacceptable.

Even though none of the dogs in this study experienced clinical consequences as a result of the procedure (e.g. depression, weakness, pale mucous membranes or increased capillary refill time), some important facts deserve attention and must be considered in practice. Post-donation pulse rates increased significantly in groups 1 and 2 but this phenomenon was particularly marked in the group where $15 \%$ TBV was collected, reaching very high frequencies (183.7; SD 32.7). Furthermore, $30 \%$ of the dogs in this group reached frequencies above $210 \mathrm{ppm}$, a value that was never observed in sedated animals that donated $13 \%$ TBV nor in any non-sedated donor. Considering that the collection procedures were pain-free, the authors believe that the sympathetic-stimulant effects of ketamine were the main contributors to these positive chronotropic responses, when superimposed to higher blood volume depletions. Rapid heart rates increase myocardial oxygen demands and reduce cardiac output and coronary blood flow by shortening the diastolic period, potentially increasing the risk for development of occult tachyarrhythmias (Olgin and Zipes 2012). Thus, based on our results, it seems that the collection of volumes $\geq 15 \% \mathrm{TBV}$ in sedated animals, may be considered a risky procedure that should be avoided whenever possible.

It is also important to mention that there were no differences when donors where grouped according to their breed or weight. It must be highlighted, however, that breeds with specific hemodynamic peculiarities (e.g. Greyhounds) were not included in this study, thus hampering comparisons with previous similar studies (Couto and Iazbik 2005).

Post-donation mean SAP was slightly but significantly lower in all groups, when compared to the pre-donation values, with a decrease being found in two thirds of the collections in group 1 and $80 \%$ of the collections in group 2. Systolic arterial pressure is related to the left ventricular stroke volume, which in turn is highly dependent on preload (Egner 2003). Therefore, the reduction of SAP is probably a direct consequence of the blood volume depletion. Furthermore, at the high cardiac rates induced by both blood depletion and ketamine effect, the decreased diastolic duration results in less ventricular filling (preload) with subsequent lower stroke volumes (Olgin and Zipes 2012). Our post-donation SAP variations are similar to those previously published in non-sedated blood donor Greyhounds (Couto and Iazbik 2005).

The ketamine sympathetic-stimulant effects lead to an increased peripheral vascular resistance (Egner 2003) that partially compensates the blood depletion effects by increasing the DAP. However, 
this compensation seems to be limited since the post-donation increase of DAP was only significant in dogs from group 1.

It is important to highlight the large variability of arterial blood pressure values. It is known that individual responses to blood depletion depend on different sympathetic tones, as well as on different pre-donation anxiety states. Two dogs experienced non-symptomatic mild to moderate hypotension after blood collections (SAP 77-97 $\mathrm{mmHg}$; DAP 51-57 mmHg), one from group 1 and one from group 2 . These values were considered to represent mild to moderate hypotension, according to published reference values of hypotensive episodes in awake dogs (mild: SAP/DAP < 100/60 mmHg; moderate: < 90/50 mmHg) (Egner 2003). In humans, a SAP lower than $75 \mathrm{mmHg}$ may lead to a syncopal episode (Trouern-Trend et al. 1999) but, to the authors' knowledge, no studies addressed such correlations in dogs. Postdonation measurements were performed with dogs still under sedative effects and none demonstrated clinical signs after recovery from sedation. This could be due to the stress-related secretion of catecholamine (Egner 2003) during the euphoric state after full recovery from sedation, which may increase arterial blood pressure. A previous study demonstrated that when the animals return to a standing position after blood donation in lateral recumbency, there was a rapid increase of arterial blood pressure (Couto and Iazbik 2005), supporting our hypothesis.

Overall, our results suggest that it is safe to collect up to $13 \% \mathrm{TBV}$ in canine donors sedated with ketamine and diazepam and that the collection of higher volumes could induce hemodynamic variations that may compromise the harmlessness of the procedure.

\section{ACKNOWLEDGMENTS}

The authors are grateful to Instituto Português do Sangue e da Transplantação and Hospital
Veterinário do Porto for their support of this project. This work was supported by the Portuguese Foundation for Science and Technology (grant SFRH /BD/43946/2008).

\section{RESUMO}

Contexto: Não existe consenso em relação ao volume de sangue que pode ser recolhido com segurança em cães doadores, variando de 11 a $25 \%$ do seu volume total de sangue (VTS). Até o momento nenhum estudo prévio avaliou o efeito das doações de sangue em animais sedados. Objetivo: Avaliar os efeitos hemodinâmicos da recolha de sangue em animais sedados e não sedados, e compreender se esses efeitos eram dependentes do volume de sangue recolhido. Materiais e Métodos: Foram realizadas 53 doações de $13 \%$ do VTS e 20 doações de $15 \%$ do VTS em cães sedados com diazepam e ketamina. Adicionalmente, um total de 30 recolhas de sangue de $13 \%$ do VTS e 20 recolhas de $15 \%$ do VTS foram realizadas em cães não sedados. Antes e 15 minutos depois das doações de sangue, foram registadas as pressões arteriais, medidas de forma não invasiva, e a frequência do pulso. Resultados: Após as doações, as frequências do pulso aumentaram significativamente em ambos os grupos sedados, com mais intensidade nas recolhas de 15\% do VTS. A pressão arterial sistólica diminuiu significativamente nestes grupos, enquanto a pressão arterial diastólica aumentou significativamente nas doações de $13 \%$ do VTS. Os cães não sedados revelaram uma diminuição pequena, porém significativa, da pressão arterial sistólica. Nenhum animal desenvolveu sinais clínicos relativos a doação. Conclusão: Estes resultados sugerem que as recolhas de $15 \%$ do VTS em dadores sedados induzem alterações hemodinâmicas que podem comprometer a segurança deste procedimento, enquanto em cães não sedados as dádivas parecem não ter efeitos deletérios.

Palavras-chave: doação de sangue, cão, sedação, volume.

\section{REFERENCES}

Authement JM. 1991. Preparation of components. Adv Vet Sci Comp Med 36: 171-185. 
COUNCIL OF EUROPE. 2011. Principles of Component Preparation. In: Guide to the preparation, use and quality assurance of blood components, $16^{\text {th }}$ ed., Strasburg: Council of Europe Publishing, p. 59-81.

CoUTO CG AND IAZBIK MC. 2005. Effects of blood donation on arterial blood pressure in retired racing Greyhounds. J Vet Intern Med 19: 845-848.

EGNER B. 2003. Blood pressure measurements - Basic principles and Practical Application. In: Egner B et al. (Eds), Essential facts of blood pressure in dogs and cats, 1 st ed., Berlin: Parey Buchverlag im Blackwell Verlag $\mathrm{GmbH}$, p. 1-14.

Ford RB AND MAZZAFERRO EM. 2006. Emergency care. In: Ford RB and Mazzaferro EM (Eds), Kirk and Bistner's Handbook of Veterinary Procedures and Emergency Treatment, $8^{\text {th }}$ ed., Missouri: Saunders Elsevier, p. 1-291.

Gibson G AND ABrams-OGg A. 2012. Canine Transfusion Medicine. In: Day MJ and Kohn B (Eds), BSAVA Manual of Canine and Feline Haematology and Transfusion Medicine, $2^{\text {nd }}$ ed., Gloucester: British Small Animal Veterinary Association, p. 289-307.

JAHR JS, LURIE F, BEZDIKIAN V, DRIESSEN B AND GUNTHER RA. 2008. Measuring circulating blood volume using infused hemoglobin-based oxygen carrier (oxyglobin) as an indicator: verification in a canine hypovolemia model. Am J Ther 15: 98-101.

KAKAIYA R, ARONSON CA AND JULleis J. 2011. Whole Blood Collection and Component Processing at Blood Collection Centers. In: Roback JD (Ed), Technical Manual, $17^{\text {th }}$ ed., Bethesda: American Association of Blood Banks, p. 187226.

LESTER S. 2012. Canine Whole Blood Collection. In: Lester S (Ed), Blood Banking Manual, $1^{\text {st }}$ ed., http://www.vin.com/ doc $/$ id $=5482548$.

LYSA P AND POSNER PB. 2009a. Injectable anesthetic agents. In: Riviere JE and Papich MG (Eds), Veterinary Pharmacology and Therapeutics, $9^{\text {th }}$ ed., Iowa: WileyBlackwell, p. 265-299.

LYSA P AND POSNER PB. 2009b. Sedative agents: Tranquilizers, alpha-2 agonists, and related agents. In: Riviere JE and Papich MG (Eds), Veterinary Pharmacology and Therapeutics, $9^{\text {th }}$ ed., Iowa: Wiley-Blackwell, p. 337-380.
MATHEwS KA, ScotT H AND ABRAMS-OGG A. 2006. Transfusion of blood products. In: Mathews KA (Ed), Veterinary Emergency and Critical Care Manual, $2^{\text {nd }}$ ed., Ontario: Lifelearn, p. 667-681.

NeWman BH. 2004. Blood donor complications after wholeblood donation. Curr Opin Hematol 11: 339-345.

Newman BH, Pichette S, Pichette D and DzaKa E. 2003 Adverse effects in blood donors after whole-blood donation: a study of 1000 blood donors interviewed 3 weeks after whole-blood donation. Transfusion 43: 598-603.

OLGIN J AND ZIPES DP. 2012. Specific arrhythmias: diagnosis and treatment. In: Leonard LS (Ed), Braunwald's Heart Disease, $9^{\text {th }}$ ed., Philadelphia: Elsevier Sauders, p. 771-824.

PlumB DC. 2005. In: Plumb DC (Ed), Plumb's Veterinary Drug Handbook, $5^{\text {th }}$ ed., Iowa: Blackwell Publishing, p. 631-636.

PosT GS 2000. Hemapheresis. In: Weiss DJ and Wardrop KJ (Eds), Schalm's Veterinary Hematology, $5^{\text {th }}$ ed., Philadelphia: Lippincott Williams \& Wilkins, p. 869-873.

SCHNEIDER A. 1995. Blood Components Collection, Processing and Storage. Vet Clin North Am Small Anim Pract 25: 1245-1261.

Trouern-Trend JJ, CABle RG, BADON SJ, Newman BH AND POPOVSKY MA 1999. A case-controlled multicenter study of vasovagal reactions in blood donors: influence of sex, age, donation status, weight, blood pressure, and pulse. Transfusion 39: 316-320.

UK Blood Transfusion SERVICES. 2005. Care and Selection of Blood Donors. In: Guidelines for the blood transfusion in the United Kingdom, $7^{\text {th }}$ ed., Norwish: The Stationery Office, p. 21-27.

Wieling W, France CR, VAN DiJK N, Kamel H, ThiJs RD AND TOMASULO P. 2011. Physiologic strategies to prevent fainting responses during or after whole blood donation. Transfusion 51: 2727-2738.

ZERVOU EK, Ziciadis K, KARABINI F, XANTHI E, Chrisostomou E AND Tzolou A. 2005. Vasovagal reactions in blood donors during or immediately after blood donation. Transfus Med 15: 389-394. 